\title{
Artery of Percheron as a Rare Feeder of Hemorrhagic Thalamic Arteriovenous Malformation: A Case Report and Literature Review
}

This article was published in the following Dove Press journal:

International Journal of General Medicine

\author{
Mengchao Zhang ${ }^{1, *}$ \\ Zheng Feng ${ }^{2}$,* \\ Weidong $\mathrm{Yu}^{3}$ \\ Chao Fu (iD ${ }^{3}$ \\ 'Department of Radiology, China-Japan \\ Union Hospital of Jilin University, \\ Changchun, Mainland China; \\ ${ }^{2}$ Department of Pediatrics, China-Japan \\ Union Hospital of Jilin University, \\ Changchun, Mainland China; \\ ${ }^{3}$ Department of Neurosurgery, China- \\ Japan Union Hospital of Jilin University, \\ Changchun, Mainland China
}

*These authors contributed equally to this work

\begin{abstract}
Arteriovenous malformation (AVM) fed by the artery of Percheron (AOP) is extremely rare, with only one case described in the literature to date. We herein present a case of a 43-year-old female with hemorrhagic thalamic AVM mainly supplied by the AOP, who subsequently underwent conservative management and recovered well except for mild right hemiparesis. This case highlights that the AOP is a rarely recognized but clinically significant entity and should be identified when dealing with AOP-associated neurovascular disorder as described.
\end{abstract}

Keywords: artery of Percheron, anatomic variant, thalamic hemorrhage, arteriovenous malformation

\section{Introduction}

According to the Percheron's classification, there are four anatomic variants of blood supply to the midbrain and thalami. ${ }^{1}$ In type I, the most common variant, paired thalamic and midbrain perforating arteries arise from the bilateral P1 segments of the posterior cerebral artery (PCA) individually. In type II, multiple perforating vessels (type IIa) or a single unpaired trunk (the artery of Percheron, AOP) originates from the unilateral P1 segment (type IIb) supplying the bilateral paramedian thalami and rostral midbrain. In type III, an arterial arcade bridges the bilateral P1 segments giving out multiple small branches to the midbrain and thalami.

To date, the most frequent event regarding the AOP is symmetric bilateral thalamic infarcts, accounting for approximately $0.1-2 \%$ of all ischemic strokes. ${ }^{2-5}$ The symptomatology of the AOP stroke includes altered mental status, oculomotor abnormality, memory impairment, behavioral amnesic impairment, aphasia or dysarthria, hemiplegia, and cerebellar signs. ${ }^{2-7}$ It is worthy of note that the AOP is rarely seen in most of the reported cases because it is too small to be visualized on routine brain imaging.

Notably, the AOP as a feeding artery of an arteriovenous malformation (AVM) is exceedingly rare, and only one case, to our best knowledge, has been reported. ${ }^{6}$ We herein present a case of a 43-year-old woman with hemorrhagic thalamic AVM mainly fed by the AOP, and the potential clinical importance of this variant, as well as the treatment strategy of the AOP-associated AVM, is discussed. 

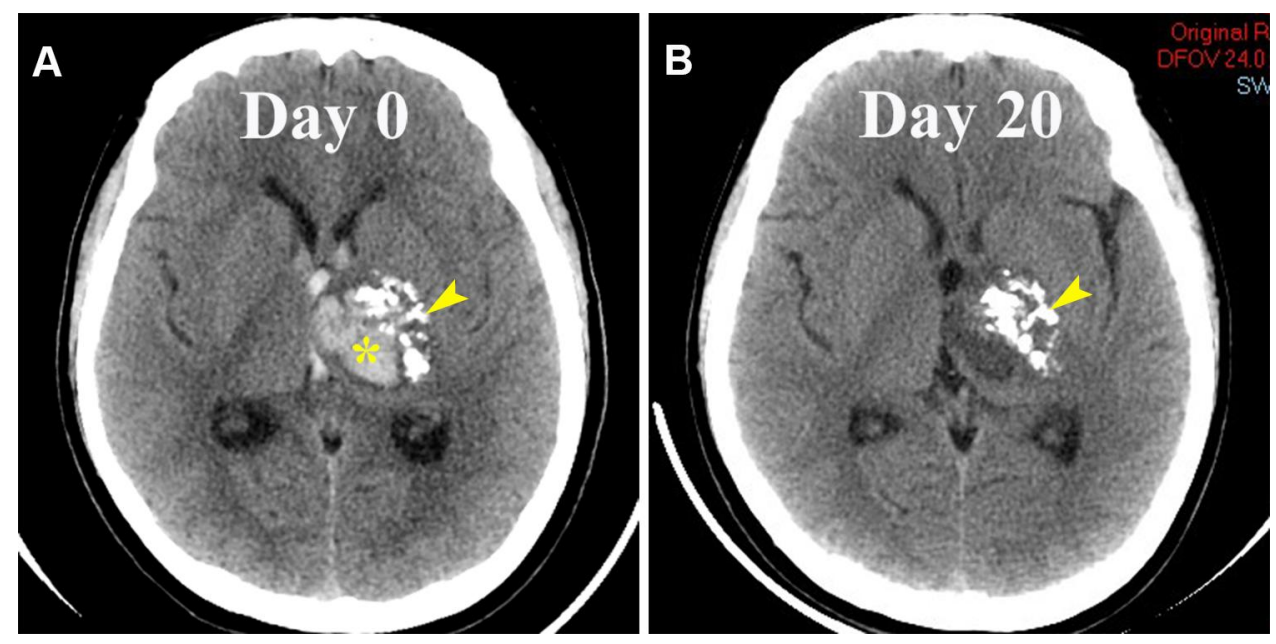

Figure I Brian computed tomography (CT) image (A) showing a left thalamic hemorrhage (asterisk) adjacent to a calcified lesion (arrowhead), extending into the ventricular system. Head CT image on day 20 (B) showing that the hematoma was spontaneously resolved and the adjacent calcifications (arrowhead) existed.

\section{Case Presentation}

A previously healthy 43-year-old female was initially admitted to another hospital with a sudden onset of severe headache, nausea and right hemiparesis (1/5). Non-contrast brain computed tomography (CT) revealed a left thalamic hemorrhage with an adjacent calcified lesion and intraventricular hemorrhage (Figure 1A). No evidence of acute hydrocephalus was observed. Conservative therapy was instituted, and she was discharged 20 days later with mild right hemiparesis (4/5). Subsequently, the patient was referred for further evaluation. Head CT revealed the disappearance of the hematoma (Figure 1B). Catheter-based angiography showed an AVM fed by a tortuous AOP arising from the left PCA and draining upward through the left internal cerebral vein into the vein of Galen (Figure 2). The P1 segment of the ipsilateral PCA was not absent or hypoplastic.
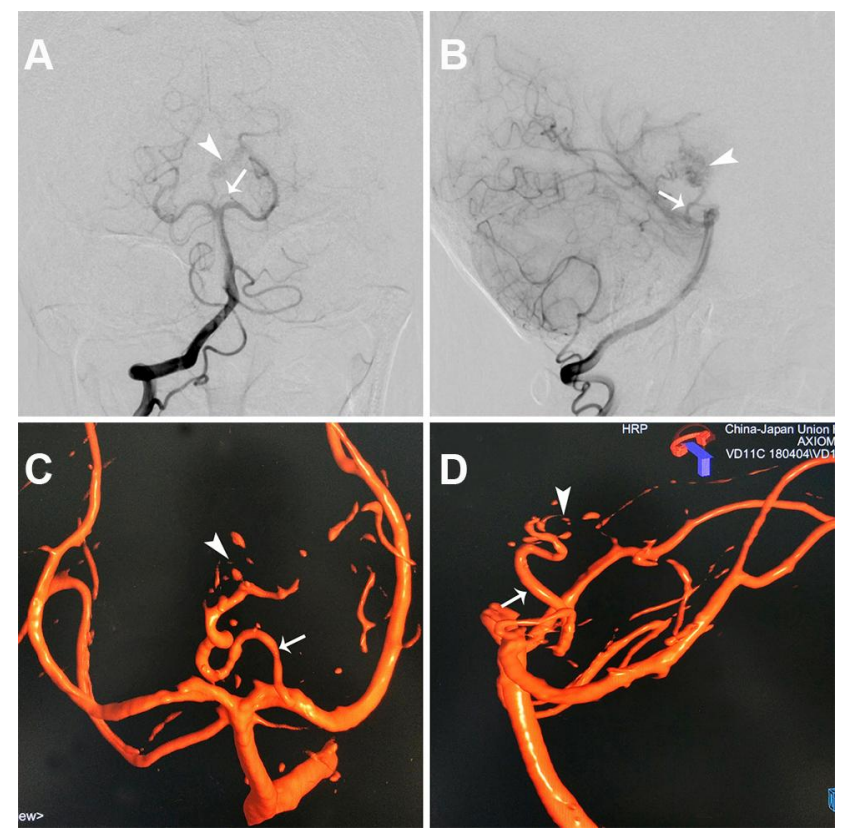

Figure 2 Catheter-based angiograms (A-D) revealing an artery of Percheron (arrow) arising from the left posterior cerebral artery (PCA), running upward, then taking a marked tortuous course, and feeding an arteriovenous malformation (AVM, arrowhead) in the left thalamus. The AVM drained into the vein of Galen through the left internal cerebral vein. Please note that the ipsilateral PI segment of the PCA was not absent or hypoplastic. 
Endovascular embolization of the AVM via the AOP as the first choice was recommended; moreover, microsurgical resection or stereotactic radiosurgery was provided an alternative option. However, she declined to undergo intervention given that the risks, and thereafter, was treated conservatively. Her neurological condition remained stable during a 1-year follow-up.

\section{Discussion}

To date, the prevalence of AOP is unclear because of its rarity. AOP often poses a diagnostic challenge because it is too small to be seen by routine brain imaging. It is noteworthy that the $\mathrm{V}$ sign on axial fluid-attenuated inversion recovery and/or diffusion-weighted imaging, a V-shaped hyperintensity along the pial surface of the midbrain in the interpeduncular fossa, was identified in $38 \%$ of all cases and $67 \%$ of cases with AOP infarction, respectively. ${ }^{5}$ Moreover, AOP has been found during a neuroendoscopic surgery for suprasellar arachnoid cyst. ${ }^{7}$

AOP may be of clinical importance in particular circumstances, such as diagnostic or therapeutic procedure because the injury of this artery during neuroendoscopic surgery and cerebral angiography has been reported to result in acute bilateral thalamic infarcts. ${ }^{89}$

Notably, AOP is rare but potentially involved in hemorrhagic AVM. As far as we know, only one case has been previously presented in the literature (Table 1). ${ }^{6}$ Moreover, the treatment challenge can exist when dealing with AOPassociated AVM. Motegi et al failed to embolize a thalamic AVM fed by AOP due to the inaccessibility of the thalamoperforating artery via the tortuous AOP $^{6}$ In this study, endovascular embolization of the AVM nidus via the AOP seemed to be feasible. As such, we recommended endovascular embolization of the AVM as the first choice. However, it should be mentioned that AOP injury or thrombosis may carry a risk of bilateral thalamic infarcts. Moreover, the AVM can also be amenable to resection if a surgical corridor is available through the hematoma, as described in a previous study. ${ }^{6}$ In addition, stereotactic radiosurgery has become increasingly recommended for the AVMs less than $3 \mathrm{~cm}$ in diameter and located in deep or eloquent areas of the brain, with a reported cure rate of $81 \%-90 \% .^{10}$ Although this method avoids a craniotomy, its main risks are twofold. First, the radiation can induce injury to the adjacent brain tissues; second, a latency period of approximately 1-3 years exists before potentially complete obliteration, in which a risk of bleeding remains. ${ }^{10,11}$ Our patient thought that the risks of the above-mentioned treatment options outweighed the benefits, and chose conservative treatment.

\section{Conclusion}

AOP is a rarely recognized but clinically significant anatomic variant, and thus identifying this vessel is of importance when treating AOP-associated neurovascular disorder as described in this study.

\section{Data Sharing Statement}

The authors declare that they had full access to all of the data in this study, and the authors take complete responsibility for the integrity of the data. All original data are available in the China-Japan Union Hospital of Jilin University, Changchun, China. Data used to support the findings of this study are available from the corresponding author upon request.

\section{Ethics and Consent Statement}

Ethical approval was obtained by the ethics committee of the Ethics Review Board of the China-Japan Union Hospital of Jilin University.

Table I Reported Cases with AVM Fed by the AOP

\begin{tabular}{|l|l|l|l|l|l|l|l|}
\hline Year & Authors & $\begin{array}{l}\text { Sexl } \\
\text { Age } \\
\text { (Years) }\end{array}$ & Presentation & Hemorrhage & AOP Origin & Treatment & Outcome \\
\hline 2014 & $\begin{array}{l}\text { Motegi } \\
\text { et al. }\end{array}$ & F/I2 & $\begin{array}{l}\text { Coma, right } \\
\text { hemiparesis }\end{array}$ & $\begin{array}{l}\text { Left thalamic hemorrhage } \\
\text { with ventricular extension, } \\
\text { acute hydrocephalus }\end{array}$ & $\begin{array}{l}\text { Contralateral } \\
\text { PI segment }\end{array}$ & $\begin{array}{l}\text { Bilateral external ventricular } \\
\text { drainages, embolization of AVM } \\
\text { failed } \rightarrow \text { surgical resection }\end{array}$ & Good \\
\hline 2019 & $\begin{array}{l}\text { Present } \\
\text { study }\end{array}$ & F/43 & $\begin{array}{l}\text { Headache, } \\
\text { nausea, right } \\
\text { hemiparesis }\end{array}$ & $\begin{array}{l}\text { Left thalamic hemorrhage } \\
\text { with ventricular extension, } \\
\text { no acute hydrocephalus }\end{array}$ & $\begin{array}{l}\text { Ipsilateral PI } \\
\text { segment }\end{array}$ & Observation & Good \\
\hline
\end{tabular}

Abbreviations: AOP, artery of Percheron; AVM, arteriovenous malformation; F, female. 


\section{Consent for Publication}

A written permission for the use of patient data for publication was obtained.

\section{Author Contributions}

All authors made substantial contributions to acquisition of data, or analysis, conception and design, and interpretation of data; took part in drafting the article or revising it critically for important intellectual content; gave final approval of the version to be published; and agree to be accountable for all aspects of the work.

\section{Funding}

The authors declared that this case has received no financial support.

\section{Disclosure}

The authors declare that they have no competing interests.

\section{References}

1. Percheron G. The anatomy of the arterial supply of the human thalamus and its use for the interpretation of the thalamic vascular pathology. Z Neurol. 1973;205(1):1-13. doi:10.1007/BF00315956

2. Kichloo A, Jamal SM, Zain EA, Wani F, Vipparala N. Artery of Percheron infarction: a short review. J Investig Med High Impact Case Rep. 2019;7:2324709619867355. doi:10.1177/2324709619867355
3. Griessenauer CJ, Loukas M, Tubbs RS, Cohen-Gadol AA. The artery of Percheron: an anatomic study with potential neurosurgical and neuroendovascular importance. Br J Neurosurg. 2014;28(1):81-85. doi:doi:10.3109/02688697.2013.812181

4. Kocaeli H, Yilmazlar S, Kuytu T, Korfali E. The artery of Percheron revisited: a cadaveric anatomical study. Acta Neurochir (Wien). 2013;155(3):533-539. doi:doi:10.1007/s00701-012-1548-1

5. Lazzaro NA, Wright B, Castillo M, et al. Artery of percheron infarction: imaging patterns and clinical spectrum. AJNR Am J Neuroradiol. 2010;31(7):1283-1289. doi:doi:10.3174/ajnr.A2044

6. Motegi H, Terasaka S, Shiraishi H, Houkin K. Thalamic arteriovenous malformation fed by the artery of Percheron originating from the contralateral posterior cerebral artery in a child. Childs Nerv Syst. 2014;30(7):1313-1315. doi:doi:10.1007/s00381-013-2343-x

7. Shukla D. Neuroendoscopic view of artery of percheron. $\mathrm{Br}$ J Neurosurg. 2017;31(5):630. doi:doi:10.1080/02688697.2017.1302075

8. Luther N, Cohen A, Souweidane MM. Hemorrhagic sequelae from intracranial neuroendoscopic procedures for intraventricular tumors. Neurosurg Focus. 2005;19(1):E9. doi:doi:10.3171/foc.2005.19.1.10

9. Lin PC, Lee CW, Liu HM, Xiao FR. Acute infarction in the artery of Percheron distribution during cerebral angiography: a case report and literature review. J Radiol Case Rep. 2018;12(7):1-9. doi: doi:10.3941/jrcr.v12i7.3318

10. Friedlander RM. Clinical practice. Arteriovenous malformations of the brain. N Engl J Med. 2007;356(26):2704-2712. doi:doi:10.1056/ NEJMcp067192

11. Lawton MT, Rutledge WC, Kim H, et al. Brain arteriovenous malformations. Nat Rev Dis Primers. 2015;1:15008. doi: doi: $10.1038 /$ nrdp. 2015.8
International Journal of General Medicine

\section{Publish your work in this journal}

The International Journal of General Medicine is an international, peer-reviewed open-access journal that focuses on general and internal medicine, pathogenesis, epidemiology, diagnosis, monitoring and treatment protocols. The journal is characterized by the rapid reporting of reviews, original research and clinical studies

\section{Dovepress}

across all disease areas. The manuscript management system is completely online and includes a very quick and fair peer-review system, which is all easy to use. Visit http://www.dovepress.com/ testimonials.php to read real quotes from published authors. 